\title{
Prognostic Validity of AgNOR in Pleomorphic Adenoma
}

\author{
Bacem AE Ottoman \\ Department of Maxillofacial Surgery and Diagnosis, Cairo University, Egypt
}

Copyright (C) 2015 by authors, all rights reserved. Authors agree that this article remains permanently open access under the terms of the Creative Commons Attribution License 4.0 International License

\begin{abstract}
Since the argyrophilic nucleolar organizer region (AgNOR) technique has successfully distinguished various grades of malignancies and enabled prognostic assessment, this paper traces its prognostic validity in predicting the behavior of pleomorphic adenoma (PA). Ten cases of recurrent PAs were compared, on the one hand, where AgNOR score of area fraction was measured before and after recurrence. The same findings were contrasted to ten cases of normal glandular mucosa. Diagnosing both pleomorphic adenomas was based on clinical and histological records of the archival submitted cases. The data were statistically analyzed by t-test, ANOVA, Tukey and Pearson's tests. The study concludes that AgNOR score lack the prognostic validity on testing PA, in terms of distinguishing and or predicting recurrence.
\end{abstract}

Keywords Pleomorphic Adenoma, AgNOR, Nucleolus Organizer Region, Prognosis, Recurrence

\section{Introduction}

Pleomorphic adenoma (PA) is a tumor of variable capsulation characterized microscopically by multifaceted architecture which relates to dual proliferation and co-mingling of cells with ductal or myoepithelial features in a mucoid, myxoid, chondroid and, less commonly, osseous stroma. Monomorphic adenomas and myoepitheliomas are homogeneous monophasic variants of MA. PAs prefer the parotid gland (approximately 80\%) while submandibular glands and minor salivary glands, among other miscellaneous sites, are less frequently affected ${ }^{[1]}$. The recurrence rate of $\mathrm{PA}$ is reported to be frantic. Given the multitude of predisposing factors of recurrence, this study measure the prognostic validity of using the argyrophilic nucleolar organizer region staining (AgNOR) technique, a valued histochemical stain, in drawing a line toward contouring and understanding the high rate of recurrence ${ }^{[2]}$.

Nucleolar organizer region (NOR) silver-stainability is greatly influenced by several factors, including (1) the fixatives: alcohol-based fixatives are superior to formalin-fixed ones, in rendering more intense and specific
AgNOR protein visualization; (2,3) temperature and duration: the two variables are inversely related to one other: the higher the temperature, the shorter the time required for selective NOR visualization. When the staining reaction is prolonged beyond the optimal time for selective NOR visualization, other nucleolar components are progressively stained until single NORs are no longer detectable and the whole nucleolus appears homogeneously stained by silver; and (4) synthetic mountant media: the use of natural mountant media, such as "Canada Balsam", allows silver-stained slides to be perfectly preserved for a very long time ${ }^{[3,4]}$.

In order to achieve a definitive standardization of NOR silver-staining, in 1993 the International Committee on AgNOR Quantitation was established and, two years later, the Guidelines for AgNOR Quantification were defined. On the basis of these considerations, during the first Workshop "AgNOR in Oncology" the "International Committee on AgNOR Quantitation" strongly recommended the use of image analysis for AgNOR quantification in order to overcome these drawbacks and to obtain a more objective and reproducible AgNOR quantification. this was ushered in an operational framework which, by adopting this morphometric method, was objectively introduced as a faster and a more accurate approach; requiring no more than a digital camera mounted on a light microscope and linked to a PC, with basic morphometric software, and some familiarity with computers and statistics ${ }^{[3]}$.

In a study of the nucleolar organizer region associated proteins in minor salivary gland tumors, van Heerden et al have concluded that the overlapping of the AgNOR count between various tumors prohibited the use of this technique as an absolute criterion in establishing a final diagnosis. They suggested it to aid in differentiating between various salivary gland neoplasms but neither in predicting the tumoral recurrence nor prognosis [5]. Landini et al have claimed that nucleolar organizing regions (NORs) detected with the silver colloid method can be used in histopathology to determine the degree of cell activity, in a case of metastasizing pleomorphic adenoma of the submandibular gland [6]. For recurrence, presence of a multinodular lesion and the type of intervention performed were claimed to be significantly associated with a higher probability of relapse [7]. 


\section{Materials and Methods}

\section{A- Case Selection}

On the one hand, twelve cases of PAs were compared to their recurrence, where AgNOR score of area fraction was measured before and after recurrence. The same findings were contrasted to ten cases of nonrecurring PA. On the other hand, all were compared to ten cases of normal glandular mucosa. Diagnosing both pleomorphic adenomas was based on clinical and histological records of the archival submitted cases. AgNOR stain was evaluated to determine the proliferative activity in the lesions. Values of AgNOR score were measured. Groups were categorized as follows:

\begin{tabular}{|c|c|c|c|}
\hline & Group & $\begin{array}{l}\text { Sample } \\
\text { number }\end{array}$ & Notes \\
\hline 1 & $\begin{array}{l}\text { Control } \\
\text { group } \\
\text { (normal) }\end{array}$ & 10 & $\begin{array}{c}\text { Archival cases (extracted from } \\
\text { normal glandular tissues in minor } \\
\text { surgeries; e.g., excision of mucocele } \\
\text { with surrounding normal salivary } \\
\text { glands) }\end{array}$ \\
\hline 2 & Primary PA & 10 & $\begin{array}{c}\text { Archival cases, retrieved from record } \\
\text { of the past } 10 \text { years }\end{array}$ \\
\hline 3 & $\begin{array}{l}\text { Recurring } \\
\text { PA }\end{array}$ & 10 & $\begin{array}{l}\text { The same patients: identity was } \\
\text { double checked by hospital numbers } \\
\text { and national ID of the patients. }\end{array}$ \\
\hline
\end{tabular}

\section{B- AgNOR Staining Procedures}

In accordance with the guidelines of the International Committee on AgNOR staining, four-micron unstained sections, obtained from blocks of archived cases to perform the silver staining, were prepared. The tissue was deparaffinized in several changes of xylene and descending alcohol concentrations. Rehydration was then performed in several changes of distilled water. The tissue was then incubated in acid alcohol (three parts ethanol: two parts acetic acid) for $5 \mathrm{~min}$ and then rinsed in distilled water several times. Sections were immersed in sodium citrate buffer (10 mM sodium-citrate monohydrate, $\mathrm{pH}$ 6.0) in plastic Coplin jars and boil at $120^{\circ} \mathrm{C}$ for $20 \mathrm{~min}$ in wet autoclave or pressure cooker. Cool to room temperature and wash with ultrapure water. A $0.66 \%$ gelatin solution dissolved in ultrapure water was prepared, to which formic acid was added in order to make a final $0.33 \%$ solution. Pre-warm to $37^{\circ} \mathrm{C}$ the solution and the glassware where the staining reaction were then performed. Silver-nitrate was dissolved in the gelatin-formic acid solution to make a final $33 \%$ solution, and immerse the slides immediately in the solution obtained. Stain in the dark at a constant temperature of $37^{\circ} \mathrm{C}$ for 13 minutes sections were then, poured off, washed in distilled water, and dehydrated in graded alcohol. Xylene and cover were finally slipped. AgNOR stained section was examined under the light microscope (Olympus CHT, Optical Co. Ltd, Japan) using 100x Objectives. The condenser was adjusted to change light intensity and allow test visualization of the AgNORs. AgNOR counting was performed under 100 using oil immersion. The silver stained nucleoli were visualized as brown black discrete dots of variable size within the nuclei. The nuclei stain light yellow and outline of nuclei as well as cells were usually clearly visible.

\section{C- Digitalization of AgNOR Slides}

Four fields were captured at original magnification of (100x) by a digital camera mounted on light microscope, Olympus CHT, Optical.Co.Ltd, Japan, to be digitally processed by Image analysis software (Image J 1.42, NIH, USA). Images were refined, trimmed and corrected to exclude all but nuclei. The corrected images were then converted into 8-gray scale type that is automated to the optimal threshold. Automated counting of AgNOR-positive nucleoli in the selected field is conducted for measuring the degree of modification - the expressive tool of proliferation within the different variants of ossifying fibromas.

After converting the images into 8-bit images, the threshold was adjusted. Eventually, area fraction per nucleus, and area fraction per case (100 nuclei) were measured. The mean area fraction was calculated for each.

\section{D- Statistical analysis:}

Data was tabulated to be processed electronically via SPSS 16 software. The data was analyzed and histograms were diagrammed. The arithmetic mean, mode and standard deviation were calculated. This was followed by calculating Pearson's correlation ( $r$ ) test and its P-Value between area fraction per nucleus, and area fraction per case. The significant result of the $\mathrm{P}$-values meant that we reject the null hypothesis and accept the alternate one.

Intending to compare recurrent cases of PA, before and after recurrence, paired $\mathrm{T}$-Test for dependent means was used. All findings were contrasted to ten cases of normal glandular mucosa using the one-way ANOVA with post-hoc Tukey HSD test. A probability (p) of less than 0.05 was considered statistically significant.

\section{Results}

Four captures of the most cellular areas were pictured at a magnification power of $100 \times$, where area fractions per nucleus and per case were calculated. The diagnosis of PAs was based on the histological examination of the H\&E slides (Figure 1). The AgNOR stained sections (figure 2) was measured as described earlier.

There was a strong correlation between the mean AgNOR score of area fraction per nucleus and its analogous score per case (100 nuclei) where Pearson's coefficient $\mathrm{R}$ was 0.86 $(\mathrm{P}-\mathrm{Value}=0.00033)$. This result was significant at $\mathrm{p}<0.05$. Therefore, using either the mean AgNOR score of area fraction per nucleus or per case should pose no difference. To simplify, this paper designated it as "the mean AgNOR score of area fraction". 


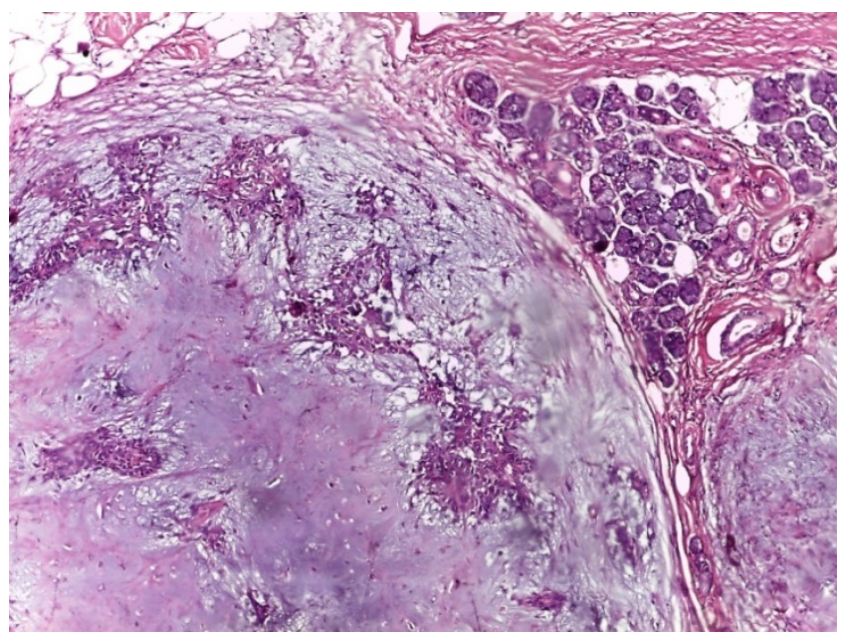

Figure 1. A photomicrograph of H\&E stained histological picture showing the classical appearance of PA; dominant chondroid differentiation. (original magnification $10 \times$ )

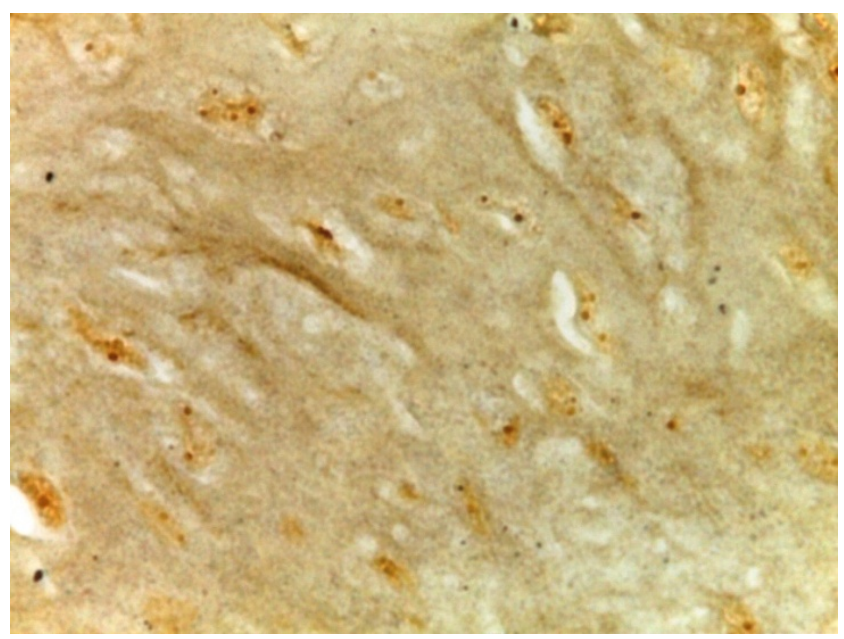

Figure 2. A photomicrograph of $\mathrm{AgNOR}$ stained section showing the low proliferative activity at the lesional center. (Original magnification 100×).

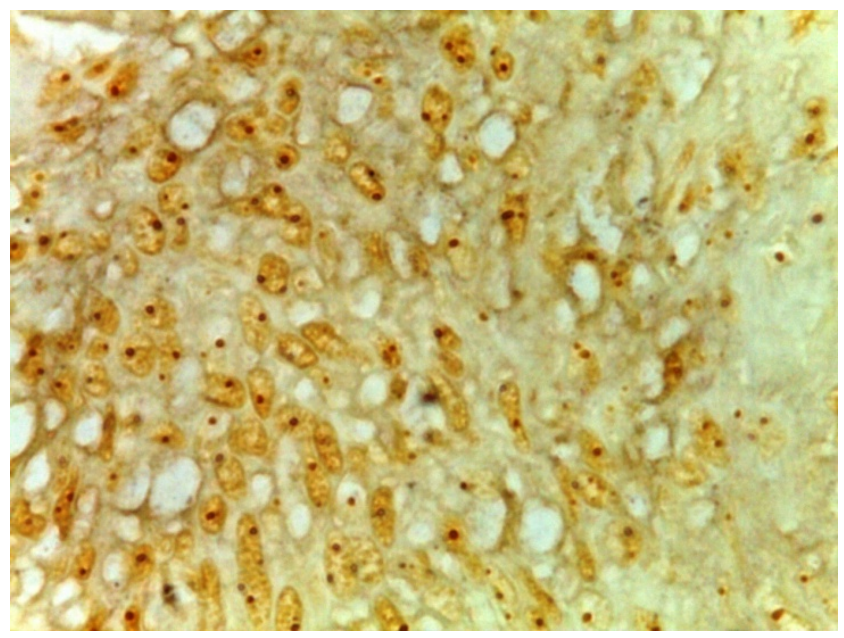

Figure 3. A photomicrograph of AgNOR stained section showing relatively higher cellular activity at the periphery of the lesion. (Original magnifications $100 \times$ ).

Regarding the difference between the mean AgNOR score of area fraction of the twelve cases of PA and their recurrences, the value of $\mathrm{t}$-test was -1.092513 . The pertaining value of $p$ was 0.300228 . The result was not significant at $\mathrm{p} \leq 0.05$.The F-statistic of ANOVA was 2.8562 whose corresponding $p$-value was 0.0506 . This suggested no significant difference between control group, primary PAs, and recurring PAs. The Tukey HSD test, could not add to the aforementioned result. The Tukey HSD inference read "insignificant" between the three studied groups $(\mathrm{p}>0.05)$.

Table 1. The Tukey HSD of the studied groups

\begin{tabular}{lccc}
\hline Groups & $\begin{array}{c}\text { Tukey } \\
\text { HSD Q } \\
\text { statistic }\end{array}$ & $\begin{array}{c}\text { Tukey HSD } \\
\text { p-value }\end{array}$ & $\begin{array}{c}\text { Tukey } \\
\text { HSD } \\
\text { inference }\end{array}$ \\
\hline Normal vs Primary PA & 3.3909 & 0.0956470 & insignificant \\
\hline $\begin{array}{l}\text { Normal vs Recurring } \\
\text { PA }\end{array}$ & 2.1769 & 0.4268350 & insignificant \\
\hline $\begin{array}{l}\text { Primary PA vs } \\
\text { Recurring PA }\end{array}$ & 1.2797 & 0.7802178 & insignificant \\
\hline $\begin{array}{l}\text { Primary PA vs } \\
\text { non-recurring PA }\end{array}$ & 3.3909 & 0.0956470 & insignificant \\
\hline $\begin{array}{l}\text { Recurring PA vs } \\
\text { non-recurring PA }\end{array}$ & 2.1769 & 0.4268350 & insignificant \\
\hline
\end{tabular}

\section{Discussion}

Pleomorphic adenoma (PA) is a tumor of variable capsulation, characterized microscopically by an impressive degree of morphological diversity. There appears to pertain to dual proliferation and co-mingling of cells with ductal or myoepithelial features in a mucoid, myxoid, chondroid and, less commonly, osseous stroma [2].

The lower pole of the parotid gland is the commonest location but deep lobe tumors can present as a parapharyngeal mass. Occasional to the tumor sites is the involvement of the accessory parotid. Pleomorphic adenomas usually are slow growing painless masses. Small tumors typically form smooth, mobile, firm lumps but larger tumors tend to become bossellated and may attenuate the over lying skin or mucosa. Some cases may reach a grotesque size. Multifocal, recurrent tumors may show some fixation to the underlying structures. PAs are seen in solitary, synchronous or metachronous paradigms. Association with other tumors, particularly Warthin tumor, in the ipsilateral or contralateral gland was also reported [2,3,8-13].

Histologically, the essential components of PA are (1) the capsule which varies in thickness, deficiency, ditching and presence (2) epithelial and myoepithelial cells which include a wide variety of cell types including cuboidal, basaloid, squamous, spindle cell, plasmacytoid and clear cells, mucous acinar sebaceous or rarely serous acinar cells - arranged in sheets or ductlike structures. Their nuclei are usually vacuolated, without prominent nucleoli or any conspicuous mitotic activity, and (3) mesenchymal or stromal elements which reveal mucoid/myxoid, cartilaginous or hyalinised and sometimes this tissue forms the bulk of the tumor. PAs that have a lipomatous stromal component of $90 \%$ or more 
have been called lipomatous PA. In recurrent lesions, more extensive inflammation, necrosis, squamous metaplasia, increase in mitotic figures and some cellular atypia are observed. Cystic degenerationa with a perineoplastic rimming around the central cavity were also described $[8,10$, 13].

Pleomorphic adenomas have high tendency to recur and to develop malignancies. Recurrences are rare in the minor glands but in a metaanalysis of parotid tumours $3.4 \%$ of tumors recurred after 5 years and $6.8 \%$ after 10 years with a range of $150 \%$. [14].

Cytogenetic causative factors were pedantically scrutinized, revealing abnormal rearrangements involving 8q12 (PLAG1 gene), 12q1315, where translocations in $\mathrm{t}(3 ; 8)(\mathrm{p} 21 ; \mathrm{q} 12), \quad \mathrm{t}(5 ; 8)(\mathrm{p} 13 ; \mathrm{q} 12) \quad, \quad \mathrm{t}(9 ; 12)(\mathrm{p} 24 ; \mathrm{q} 1415)$ [HMGA2 gene], or an insertion ins(9;12)(p24;q12q15) were the most frequent rearrangements[8]. Immunohistochemical evaluation of $\mathrm{p} 16$, cyclin $\mathrm{d} 1, \mathrm{rb}, \mathrm{e} 2 \mathrm{f}$ and cdk4 in recurrent pleomorphic adenoma was, within limits, promising [15].

Within the striking Perchance about the recurring predisposition, tumor cells are highly expected to possess low biological requirements: an exegesis which may account for the neoplastic cellular survival on splitting into an operative site. Many recurrent pleomorphic adenomas are multifocal and some are so widely distributed that surgical control becomes impossible. Another possible justification for recurrences or persistence in pleomorphic adenoma is the diffluent nature of predominantly mucoid tumors [8].

There are no reliable histological criteria for predicting recurrences of PA. Accordingly, hope is groped by trying some indicators such as proliferative markers. In a study of the proliferative activity of the structural components of normal salivary glands and characteristic histological areas in salivary PA, by visualization of AgNORs, the mean number of AgNORs in this portion was 1.80 within the intercalated ducts, which was significantly higher than in the other epithelial parts. This indicated a relative proliferative activity of the intercalated ducts. Solid nests in PA revealed a higher AgNOR score than scattered stromal neoplastic cells [16]. Another study considered the higher cellular activity than the chondroid cells indicative of malignant transformation [17]. On the other hand, AgNOR count and area, in a third study, did not show any significant differences between recurring and nonrecurring PA[18].

As regards this study, the morphometric analysis of AgNOR quantification was not useful in highlighting the prognosis of the studied PAs. The quantification of AgNOR count differed sensitively according to the measured site in the same lesion. Variable scores were charted at the peripheral (capsular) area. In four cases, the paraffin blocks of the capsule were missing.

\section{Conclusions}

The recurrence of the PAs is not related to the inherent proliferative activity of the lesion. Accordingly, AgNOR is not valid in predicting the prognosis of pleomorphic adenomas.

\section{REFERENCES}

[1] Neville B, Damm D, Allen C, Bouquot J: Oral and maxillofacial pathology. St. Louis: Saunders/Elsevier; $3^{\text {rd }}$ edition 2009.

[2] Regezi J, Sciubba J, Jordan R: Oral Pathology. Clinical Pathologic Correlations, Saunders, Philadelphia, Pa, USA, $5^{\text {th }}$ edition, 2007.

[3] Trerè D: AgNOR staining and quantification. Micron. 2000; $31: 127-31$.

[4] Crocker J, Boldy D and Egan M: How should we count AgNORs? Proposals for a standardized approach. J pathol $1989 ; 158(3), 185-8$.

[5] van Heerden WF, Raubenheimer EJ: Evaluation of the nucleolar organizer region associated proteins in minor salivary gland tumors. J Oral Pathol Med. $1991 ; 20(6): 291-5$. DOI: $10.1111 / j .1600-0714.1991 . t b 00930 . x$

[6] Landini G, Kitano M, Urago A: [Nucleolus organizer regions (NORs) in metastasizing pleomorphic adenoma]. An Fac Odontol. 1990;(26):49-61.

[7] Redaelli de Zinis LO, Piccioni M, Antonelli AR, Nicolai P. Management and prognostic factors of recurrent pleomorphic adenoma of the parotid gland: personal experience and review of the literature. Eur Arch Otorhinolaryngol. 2008; 265(4):447-52. doi: 10.1007/s00405-007-0502-y

[8] Witt RL, Eisele DW, Morton RP, Nicolai P, Poorten VV, Zbären P: Etiology and management of recurrent parotid pleomorphic adenoma. Laryngoscope. 2015;125(4):888-93. doi: 10.1002/lary.24964.

[9] Werner RL, Castle JT: Recurrent Pleomorphic Adenoma. Head Neck Pathol 2014, 8 (3)303-6

[10] Phillips PP, Olsen KD: Recurrent Pleomorphic Adenoma of the Parotid Gland: Report of 126 Cases and a Review of the Literature. Ann Otol Rhinol Laryngol 1995; 104 (2) 100-4. doi: 10.1177/000348949510400203

[11] Laskawi R, Schott T, Schrđer M: Recurrent pleomorphic adenomas of the parotid gland: clinical evaluation and long-term follow-up 1998;36(1) 48-51 DOI: http://dx.doi.org/10.1016/S0266-4356(98)90748-3

[12] Seifert G, Donath K: Multiple tumors of the salivary glands - terminology and nomenclature. Eur J Cancer B Oral Oncol 1996; 32B: 3-7.

[13] Webb AJ, Eveson J: Pleomorphic adenomas of the major salivary glands: a study of the capsular form in relation to surgical management. Clin Otolaryngol 2001; 26: 134-42.

[14] Hickman RE, Cawson RA, Duffy S: The prognosis of specific types of salivary gland tumors. Cancer 1984;54: 1620-4.

[15] Borges Soares A, Souza A, Altemani A, et al: Evaluation 
immunohistochemistry of p16, cyclin $\mathrm{d} 1, \mathrm{rb}, \mathrm{e} 2 \mathrm{f}$ and cdk4 in recurrent pleomorphic adenoma. VIRCHOWS ARCHIV 2014;465: S85-S85

[16] Landini G: Nucleolar organizing regions (NORs) in pleomorphic adenomas of the salivary glands. J Oral Pathol Med. 1990;19(6):257-60.

[17] Fujita S, Takahashi H, Okabe H: Proliferative activity in normal salivary gland and pleomorphic adenoma. A study by argyrophilic nucleolar organizer region (AgNOR) staining. Acta Pathol Jpn. 1992;42(8):573-8.

[18] Criscuolo M, Migaldi M, Collina G, Cesinaro AM, Galetti R, Lo Bianco F, Trentini G: Prognostic significance of nucleolar organizer regions in recurrent pleomorphic adenomas of salivary glands. Pathologica. 2009; 86(6): 606-11 DOI: 7617389 